\title{
What Constitutes a Good and Bad Death?: Perspectives of Homeless Older Adults
}

\author{
Eunjeong Ko, Jung Kwak, and Holly Nelson-Becker
}

\section{QUERY SHEET}

This page lists questions we have about your paper. The numbers displayed at left can be found in the text of the paper for reference. In addition, please review your paper as a whole for correctness.

Q1: Au: In the sentence beginning "Often used interchangeably with various terms such as "decent death," "quality of dying," and "ideal death" (Kehl, 2006), definitions of what constitutes a..." please specify if the correct reference cited is Steinhauser, Clipp et al., 2000 or Steinhauser, Christakis et al., 2000.

Q2: Au: In the sentence beginning "Review of existing EOL studies of community-dwelling older adults and seriously ill patients in medical settings suggests a broad..." please specify if the correct reference cited is Steinhauser, Clipp et al., 2000 or Steinhauser, Christakis et al., 2000.

Q3: Au: In the sentence beginning "Lastly, a person's religious faith and spirituality constitute an important aspect of a good death as they have profound..." please specify if the correct reference cited is Steinhauser, Clipp et al., 2000 or Steinhauser, Christakis et al., 2000.

Q4: Au: In the sentence "Study protocol was approved by the BLINDED FOR REVIEW Institutional Review Board (approval number 448042)" please replace "BLINDED FOR REVIEW" with appropriate name.

Q5: $\mathrm{Au}$ : In the sentence beginning "These themes on a good and bad death found in our study are similar to those that have been found and reported in previous studies with different populations such as terminally..." please specify if the correct reference cited is Steinhauser, Clipp et al., 2000 or Steinhauser, Christakis et al., 2000.

Q6: Au: In the sentence beginning "Also congruent with previous studies (Payne et al., 1996; Steinhauser et al., 2000; Vig \& Pearman, 2004), participants' fear of suffering physical pain..." please specify if the correct reference cited is Steinhauser, Clipp et al., 2000 or Steinhauser, Christakis et al., 2000.

Q7: Au: In the sentence beginning "These views are similar to those described in the literature which documents lack of autonomy and control over decision-making and being perceived..." please specify if the correct reference cited is Steinhauser, Clipp et al., 2000 or Steinhauser, Christakis et al., 2000.

Q8: Au: In the sentence beginning "As with previous studies (Asgeirsdottir et al., 2013; Prince-Paul, 2008; Steinhauser et al., 2000), God was symbolized as a higher being who provides hope for a ..." please specify if the correct reference cited is Steinhauser, Clipp et al., 2000 or Steinhauser, Christakis et al., 2000.

Q9: Au: Please cite Greenberg, G. A., \& Rosenheck, R. A. (2008) in text or delete from reference list.

Q10: Au: In O'Connell 2005, please add location of publisher.

Q11: Au: Please cite van der Geest, S. (2004) in text or delete from reference list.

Q12: Au: Please provide citation for Table 1 in text.

\section{TABLE OF CONTENTS LISTING}

The table of contents for the journal will list your paper exactly as it appears below:

What Constitutes a Good and Bad Death?: Perspectives of Homeless Older Adults

Eunjeong Ko, Jung Kwak, Holly Nelson-Becker 


\title{
What Constitutes a Good and Bad Death?: Perspectives of Homeless Older Adults
}

\author{
Eunjeong Ko \\ School of Social Work, San Diego State University, San Diego, California, USA
}

Jung Kwak

Department of Social Work, University of Wisconsin-Milwaukee, Milwaukee, Wisconsin, USA

Holly Nelson-Becker

School of Social Work, Loyola University Chicago, Chicago, Illinois, USA

\begin{abstract}
This qualitative study explored perspectives toward a good or bad death among 21 older homeless adults residing in transitional housing. Using grounded theory approach, the themes for a good death were (a) dying peacefully; (b) not suffering; (c) experiencing spiritual connection; and (d) making amends with significant others. Themes for a bad death were (a) experiencing death by accident or violence; (b) prolonging life with life supports; (c) becoming dependent while entering a dying trajectory; and (d) dying alone. Healthcare professionals need to develop a culturally sensitive approach for end-of-life care grounded in understanding unique needs of older homeless adults.
\end{abstract}

Facilitating a good death for individuals at the end of life (EOL) is central to achieving an important public health goal (Kehl, 2006; Watts, 2012). Hospice and palliative care have been important areas of EOL interventions to promote and facilitate a better dying experience in the last few decades (Watts, 2012). Often used interchangeably with various terms such as "decent death," "quality of what constitutes a "good death" remain diverse depending on personal values, history, needs, and social and cultural contexts of patients, families, and health care providers across various settings (Carr, 2003; Payne, Langley-Evans, \& Hillier, 1996; Steinhauser et al., 2000; Vig, Davenport, \& Pearlman, 2002).

Review of existing EOL studies of communitydwelling older adults and seriously ill patients in medical settings suggests a broad framework that helps us

Received 22 January 2014; accepted 19 August 2014.

Address correspondence to Eunjeong Ko, School of Social Work, San Diego State University, 5500 Campanile Drive, San Diego, CA 92182. E-mail: eko@mail.sdsu.edu understand and address an individual person's need to achieve a good death at the EOL (Emanuel \& Emanuel, 1998; Kehl, 2006; Ko, Cho, Perez, Yeo, \& Palomino, 2013; Steinhauser et al., 2000; Davenport, \& Pearlman, 2002). Suffering from physical pain is a dominant concern among individuals and "dying in sleep," has been commonly used to express an ideal condition for achieving a good death (Hughes, Schumacher, JacobsLawson, \& Arnold, 2008; Pierson, Curtis, \& Patrick, 2002; Vig et al., 2002; Vig \& Pearlman, 2004). According to Vig and Pearlman (2004), dying in sleep encompasses not only lack of physical pain, but also reflects the state of not knowing about impending death and thus dying peacefully or easily. However, preferences for control and awareness of the dying process are found to vary. Although some participants preferred to die in their sleep, not waking up, others wanted to maintain awareness of the dying process (Pierson et al., 2002; Vig et al., 2002). Achieving a sense of comfort is considered an important element of a good death, which professionals can support by relieving psychological or emotional distress such as anxiety, depression, and stress. Also, 
maintaining autonomy and control over one's EOL care decisions about specific medical treatment and place of care are other important aspects of a good death (Kehl, 2006; Pierson et al., 2002; Prince-Paul, 2008).

Strengthening social relationships is also a significant attribute of a good death (Kehl, 2006; Pierson et al., 2002). Individuals' desire for emotional interconnectedness with loved ones increases at the EOL (Pierson et al., 2002; Singer, Martin, \& Kelner, 1999). Spending time with family or the presence of family nearby in the dying process is perceived to enhance comfort and sense of unity and peace for most individuals (Hughes et al., 2008). But some view having family and friends around with a fear of causing distress to these loved ones (Vig \& Pearlman, 2004). Lastly, a person's religious faith and spirituality constitute an important aspect of a good death as they have profound influence on one's search ness and death (Phelps et al., 2009; Steinhauser et al., 2000; Nelson-Becker, 2006; Tarakeshwar et al., 2006).

The themes of good or bad death share some similarities, yet the meaning and content attributed to these themes vary within an individual's EOL care experiences and relationship with others in medical, social, and cultural contexts. Although the concepts of good or bad death continue to be expanded through better understanding of diverse cultural views in different populagood or bad death or the desired outcomes of EOL care.

Increasing demands for culturally competent EOL care for diverse older populations suggest that healthcare professionals need to develop understanding and vulnerable populations such as homeless individuals. Approximately 1,593,150 individuals experienced homelessness between October 2009 and September 2010, but this number only reflects those who sought emergency count (Substance Abuse and Mental Health Services Administration [SAMHSA], 2011). Further, nearly $15 \%$ are ages 51 to 61 and another $2.8 \%$ are 62 or older (SAMHSA, 2011). Homeless individuals are character-

100 ized as having deficiency in securing personal basic needs (e.g., food, shelter, clothing etc.), being estranged or isolated from family, and lacking attention from society (Song, Ratner, \& Bartels, 2005). Homeless individuals as compared to the general population have

105 greater chronic health problems and increased incidence of mental health issues (Brown, Kiely, Bharel, \& Mitchell, 2012; Garibaldi, Conde-Martel, \& O’Toole, 2005; Lebrun-Harris et al., 2013). Poor health conditions, coupled with substance use and misuse, and

110 mental health issues may heighten a risk of premature mortality and poor quality of life (Baggett et al., 2013;
McNiel, Binder, \& Robinson, 2005; Morrison, 2009). Overall, the homeless population has a three to four times greater mortality rate than the general population (O'Connell, 2005). One study with homeless adults revealed that drug overdose, cancer, and heart disease were the major causes of death (Baggett et al., 2013). Homeless patients who had been hospitalized for a drugrelated issue have a sevenfold higher risk of death from drugs as compared to the general population (Morrison, 2009). Poor health conditions are exacerbated by lack of health care access: Homeless patients experienced twice the odds of having unmet medical needs and emergency room admissions than their nonhomeless counterparts (Lebrun-Harris et al., 2013). Age differences in health problems are significant such that older homeless individuals who were age 50 and older were 3.6 times more likely to have chronic health issues than younger homeless individuals (Garibaldi, Conde-Martel, \& O'Toole, 2005). Prevalence of geriatric syndromes (e.g., functional impairment, fragility, and cognitive impairment) was higher among homeless adults as compared to the general population (Brown et al., 2012). About 58\% of homeless older adults as compared to $85 \%$ of a population-based sample reported their health as good, very good, excellent (Brown et al., 2012).

The homeless population is also at a greater risk of victimization and violence. According to Lee and Schreck (2005), 54\% of homeless adults included in the 1996 National Survey of Homeless Assistance Providers and Clients reported being victimized in any way; $21.3 \%$ had been physically assaulted while homeless. Older homeless women were more likely to be the victims of sexual assault as compared to their male counterparts (Dietz \& Wright, 2005).

A small number of studies with this vulnerable group have explored the perspectives of homeless older adults regarding attitudes toward death and dying (Song et al., 2005; Song, Ratner, Bartels, Alderton, \& Ahluwalia, 2007), and EOL care planning (Ko \& Nelson-Becker, 2013; Tarzian, Neal, \& O’Neil, 2005). These studies cited have broadened our understanding of more than just challenges, needs, and concerns regarding EOL care planning. They have also provided a foundation for understanding the perspectives of homeless individuals themselves regarding death and dying. Yet, in-depth understanding of how the concept of a good or bad death and its essential elements are defined within the unique social contexts of a homeless population is lacking. Social structures such as age, class, and gender are important components of life contexts, and the concept of death is embedded in the larger culture in which people interpret their life experiences. For the growing population of older homeless individuals who struggle to meet most basic needs such as food, shelter, and safety, the concept of a good or bad 
death might be different from the general public. Accordingly, this study aimed to explore older homeless adults' perspectives toward good and bad deaths and their concerns regarding their EOL care needs.

\section{METHODOLOGY}

\section{Study Design}

This was a qualitative study where older homeless adults at a transitional housing facility in San Diego were interviewed in person. This transitional housing facility allowed homeless adults aged 60 and older to stay up to 3 months prior to their placement in permanent housing. Study protocol was approved by the BLINDED FOR REVIEW Institutional Review Board (approval 180 number 448042).

\section{Sampling Method and Procedure}

A letter explaining the purpose of the study and the process of participation in the study was mailed to the director of the study site. Upon the director's approval, the case managers left an invitation letter on each resident's door that invited interested residents to contact Eunjeong Ko or their case manager. The eligibility criteria for study participation included being aged 60 or older, cognitively intact, and able to speak and understand English. Among the total of 36 residents at the study site, nine did not respond to the invitation and three left the transitional housing program during the recruitment period. Two participants expressed no interest in participating in the study and one participant agreed to

195 participate but was hospitalized during the study period. Prior to the interview, potential participants were screened for their ability to meet cognitive criteria. Cognitive competency was screened using the Short Portable Mental Status Questionnaire (SPMSQ; Pfeiffer, 1975). The SPMSQ consists of 10 items measuring the cognitive ability to discern person, place, and time. The participants who scored less than eight were considered to have cognitive impairments and excluded from this study. All participants met the criteria for cognitive competency. A total 21 participants completed the interviews.

\section{Data Collection}

Data were collected via face-to-face interviews by Eunjeong Ko at a private office on the study site grounds using a semi-structured interview guide. The death you described? Interviews lasted about 40-50 min. Each interview was audio-tape recorded and then transcribed by a research assistant.

\section{Data Analysis}

Data were analyzed by using a constant comparative method according to grounded theory (Padgett, 1998). In an open coding process, two researchers (Eunjeong Ko and Jung Kwak) reviewed the transcripts independently and developed the initial coding scheme. Then the authors reiteratively reviewed the transcripts to identify additional secondary coding. The authors compared coding results, which involved confirming and disconfirming categories. Any discrepancies on categories were discussed and recategorized to achieve consensus in generating themes.

Two strategies were implemented to enhance the rigor of the study: member checking and peer debriefing. Member checking was completed (Krefting, 1991; Lincoln \& Guba, 1985) to ensure whether the researcher's interpretation of the participants' perspectives was accurate. Because of the transient nature of homeless individuals and the limited length of stay at the study site, only two individual participants were engaged in member checking. In the second individual meeting at the private office of the study site, the researcher presented the raw data from the formal first session with that individual participant and asked the participants to confirm the accuracy of their comments. Themes were presented and participants were asked if the themes reflected the meanings and nuances of their interview contents. Any specific phrases that were unclear were discussed and clarified. Another strategy used was peer debriefing. Peers can play a role in guarding against a researcher's bias and providing different perspectives in consideration of study findings. This process enhances credibility (Lincoln \& Guba, 1985). The peer debriefing process used here involved peer researchers who discussed methodology and data analysis results. Two peers (including Holly Nelson-Becker) who are gerontologists and familiar with the study on this population served the role of reviewers; they provided feedback and suggestions on methodology and interpretations of data. Any potential bias in constructing questions and methodology based on the researcher's previous work with homeless populations was discussed with these two peers.

\section{RESULTS}

\section{Participant Background Characteristics}

The majority of the participants $(n=18)$ were male and the mean age was 65 years old. Eleven participants were would you describe a "good" and "bad death?"; (b) What would be the ideal or best situation in which you would envision yourself dying?; and (c) What do you think may stand in the way of you having the good

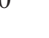

25

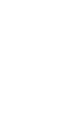

0

35


White, whereas five participants were African American and three participants were non-White Hispanic. Nine participants were divorced whereas six participants were never married. The majority of participants $(n=19$, $90.5 \%$ ) reported income less than $\$ 20,000$ per year and more than half $(n=13 ; 57.1 \%)$ had some college or college education.

Although $57 \%$ of the participants reported their health to be very good or good, $19 \%$ of the participants reported poor health. Participants indicated that they had been told by a doctor that they have health conproblem $(n=7,33.3 \%)$, diabetes $(n=4,19 \%)$, and mental health problems $(n=10,47.6 \%)$. More than half $(n=13,61.9 \%)$ reported having an experience of being admitted to an intensive care unit. Fifteen participants

$280(71.4 \%)$ had an experience of living on the street and the average length of time living on the streets was 47.3 months, nearly 4 years. About $42 \%$ reported that they had family whom they contacted at least once a month.

\section{Themes}

Interviews with participants revealed several themes defining good and bad death. Themes concerning a good and a bad death emerged in relation to multiple aspects of well-being: physical, emotional, social, and spiritual.

290 They are detailed by number of respondents in Table 2. The themes for a good death were (a) dying peacefully; (b) not suffering; (c) experiencing spiritual connection; and (d) making amends with significant others. Absence or insufficiently met needs on these domains were related to themes of a bad death but were not exactly the opposites of a good death. The themes of bad death were (a) experiencing death by accident or violence; (b) prolonging life with life supports; (c) becoming dependent while entering a dying trajectory; and (d) dying alone.

\section{What Constitutes a Good Death}

\section{Dying Peacefully}

Participants viewed "dying in sleep" as the optimal condition of a good death which was referred to also as a peaceful death. One participant stated, "A good death for me is a peaceful death. A peaceful death means just goes...go to sleep... You know, I don't want the pain. Yeah, just go to sleep when it's time, yeah" (Id\#11). Another said, "A good death is when you lay and your body doesn't work anymore" (Id\#20).

According to some participants, a peaceful death was a natural death that did not require artificial medical

TABLE 1

Participants Sociodemographic and Health Information $(N=21)$

\begin{tabular}{|c|c|c|}
\hline Demographic & $\mathrm{n}$ & $\mathrm{M}(\mathrm{SD}) / \%$ \\
\hline Age & & $65.0(4.0)$ \\
\hline Male & 18 & $85.7 \%$ \\
\hline \multicolumn{3}{|l|}{ Race } \\
\hline White & 11 & $52.4 \%$ \\
\hline Black & 5 & $23.8 \%$ \\
\hline Latino/Hispanic & 3 & $14.3 \%$ \\
\hline Other & 2 & $9.5 \%$ \\
\hline \multicolumn{3}{|l|}{ Marital Status } \\
\hline Divorced & 9 & $42.9 \%$ \\
\hline Never Married & 6 & $28.6 \%$ \\
\hline Separated & 3 & $14.3 \%$ \\
\hline Married/live together & 2 & $9.5 \%$ \\
\hline Widowed & 1 & $4.8 \%$ \\
\hline \multicolumn{3}{|l|}{ Education } \\
\hline Less than high school & 2 & $9.5 \%$ \\
\hline High school graduate & 6 & $28.6 \%$ \\
\hline Some college/college graduate & 12 & $57.1 \%$ \\
\hline Postgraduate & 1 & $4.8 \%$ \\
\hline \multicolumn{3}{|l|}{ Income } \\
\hline Less than $\$ 10,000$ & 5 & $23.8 \%$ \\
\hline$\$ 10,000-\$ 19,999$ & 14 & $66.7 \%$ \\
\hline More than $\$ 20,000$ & 2 & $9.5 \%$ \\
\hline \multicolumn{3}{|l|}{ Religion } \\
\hline Baptist/protestant /Pentecostal & 17 & $81.0 \%$ \\
\hline Catholic & 2 & $9.5 \%$ \\
\hline Atheist & 2 & $9.5 \%$ \\
\hline \multicolumn{3}{|l|}{ Self-reported health } \\
\hline Very good/good & 12 & $57.1 \%$ \\
\hline Fair & 5 & $23.8 \%$ \\
\hline Poor & 4 & $19 \%$ \\
\hline \multicolumn{3}{|l|}{ Health conditions } \\
\hline Hypertension & 16 & $76.2 \%$ \\
\hline Arthritis & 12 & $57.1 \%$ \\
\hline Heart problem & 7 & $33.3 \%$ \\
\hline Diabetes & 4 & $19.0 \%$ \\
\hline Stroke & 4 & $19.0 \%$ \\
\hline Cancer & 3 & $14.3 \%$ \\
\hline Lung problem & 2 & $9.5 \%$ \\
\hline Psychological problem & 10 & $47.6 \%$ \\
\hline Hospitalized at ICU in the past & 13 & $61.9 \%$ \\
\hline \multicolumn{3}{|l|}{ Living/social context } \\
\hline Have lived on the street & 15 & $71 \%$ \\
\hline \multicolumn{3}{|c|}{$\begin{array}{l}\text { \# of family whom they contact at least } \\
\text { once a month }\end{array}$} \\
\hline None & 10 & $57.6 \%$ \\
\hline One-two & 4 & $19 \%$ \\
\hline Three to four & 3 & $14.3 \%$ \\
\hline More than five & 4 & $19 \%$ \\
\hline
\end{tabular}

interventions to prolong life. Being able to have a peaceful moment at the EOL even if it meant dying alone was important as one participant commented below:

I mean, a good death is something where you just pass over onto the next stage. I mean... if $I$ was in a hospital ... let me envision this for you. If I was in a hospital connected to all kinds of ventilators and tubes and couldn't get out of bed and just used the bathroom in 
TABLE 2

Themes for Good and Bad Death and the Number of Respondents

\begin{tabular}{ll}
\hline Good death $(n)$ & \multicolumn{1}{c}{ Bad death $(n)$} \\
\hline Peaceful death (8) & Death by accident or violence (5) \\
Not suffering (2) & Prolonging life with life supports (2) \\
$\begin{array}{l}\text { Religious or Spiritual } \\
\text { connection (5) }\end{array}$ & Losing control and being dependent (4) \\
$\begin{array}{c}\text { Resolving personal issues } \\
\text { with family or others (3) }\end{array}$ & Dying alone (5) \\
\hline
\end{tabular}

bed... and then I die, that would not be a peaceful death. That would be a very painful death. If I die in this flophouse room behind a locked door and I just pass off tonight into the hereafter, um, that would be a good death. $(\operatorname{Id} \# 1)$

\section{Not Suffering}

Death without suffering was considered to be a good death. Suffering physical pain inflicted from disease or accident was something the participants feared: "I don't think I will like to stay long. Suffering... Bad death... It's uh... like you know, an accident or something (Id \#16). The participant was specifically concerned about his age-related infirmity: "I can just go outside and get Now that I'm older, I'm not as strong as I used to be" (Id\#10).

The above participant further added concern about no remedy for physical pain.

Less suffering physically would be a good death. I think a lot of people are scared to suffer. I'm afraid to be in horrible pain and that happens to a lot of people, I'm pretty sure. You know, they're in horrible pain and there's no kind of medication or anything that can stop it. (Id\#10)

\section{Experiencing Spiritual Connection}

A personal relationship with God or a higher power was a critical element to a good death. Participants voiced that the presence of God while dying would strengthen the sense of spiritual connection and provide companionship during the dying process: "Good death is to die with the Lord and bad death is to die without the Lord" (Id\#2); "I can think of nothing worse than dying alone. I... I don't feel alone. So even if I were

355 to die, I would not die alone. I mean, how can you die alone when you have the [presence of the] God of the universe?" (Id\#19).

While spiritual belief provided a sense of connection and hope, death was also viewed as a time for moral 360 judgment by God. A participant who grew up as a Christian identified death as an opportunity to meet
God and expressed his wish to be ready to meet that God in whom he believed.

I wouldn't mind dying out in the sun, but I would want to be ready to meet my Creator... (chuckles). I was brought up in the Christian church where they teach us that you have to have God in your heart to be able to go with Him... If we're not right with God, then we go, you know, the other way... hell... I try to live a good life. I try to help people, try not to hurt nobody... I try to follow what they tell me in church to do... I wouldn't mind um ... dying fast because they tell me that if you die fast, you'll be right there with God. (Id\#15)

\section{Making Amends with Significant Others}

Resolving remaining issues and disagreements with family and friends was another important element of a good death. Participants discussed that to experience a sense of closure and acceptance of impending death with peace would require taking care of inner conflicts, being able to express love, and apologizing to family and others. One participant said,

I'd tell them how much I love them, you know... tell them if I did ... forgive me if I did something wrong... Express my feelings and say I love them ... I want to die comfortably... surrounded by my family... everyone has, you know, different preferences. I would like to be... around my family. (Id\#16)

For some participants who have faced hardship in life, having a moment to express affection and seek reconciliation with family was important. The participant above who became emotional in recollecting her past, communicated her desire to express her love toward her family at the EOL.

Well, [I would like to] probably be with my family. Um... (pause) ... and I guess just be able to tell them I love them, you know. And well, because that's always when I like talk to my kids, tell them I love you, you know... Sometimes I wish I never brought them... I am sorry that I had them suffer...(long pause)... (teary). (Id\#15)

Another participant identified resolving his anger as an important task to accomplish in order to have a good death. Unlike others, this participant did not consider presence of family support while dying as important, but rather was concerned about the negative outcome of anger which sometimes led to violent altercation.

My living conditions aren't gonna affect [having] a good death or bad death. My lack of having a family won't affect it. But my anger issues could very well affect it. 
I express [anger] inappropriately. It's anger towards myself, but I've been expressing it inappropriately ... I'll be locked back up again. It could very well cause an unpleasant death. $(\operatorname{Id} \# 1)$

\section{What Constitutes a Bad Death}

\section{Experiencing Death by Accident or Violence}

Some participants were concerned about unexpected death caused by violence or accident. "You know... being killed by ... violence. Shot, stabbed, whatever... I don't want that. Bad death is an accident ... or a death where you'd be pinned in over rubble from an earthquake or something like that and die slowly. That kind of thing would concern me" (Id\#11). Participants perceived an abrupt ending to one's life by accident or a violent death as a bad death. They perceived death due to a natural cause as ideal. As one participant said, "I see the news and people are getting shot... A normal, natural thing is to end to your life... for your life to end as it should end in a peaceful manner" (Id\#20).

The participant who had the past drug addiction expressed her fear of dying with a drug overdose and violence. She underwent several occasions of near death in the past; the participant was concerned about the negative consequences of a tragic death on her children.

I didn't want to die that way 'cause like I said I been dead on arrival (DOA) three times from heroin and like I said there were people who would come up there and threaten to kill people... But I didn't want to die that way and I didn't wanna hurt my kids that way 'cause they already went through stuff like that. I over dosed (OD'd) one time and I put my kids outside, you know, it was in the winter time and they were trying to get back in the house and you know what? They found me laying on the kitchen floor with the tie and the needle still in my arm. (Id\#11)

Another participant expressed his concern about being involved in potential altercation with others which may cause violent death.

If I get into a fight with anybody... alright...I'm not gonna be here talking to you. You know I'll be going somewhere else ... I'll be locked back up again. It could very well cause an unpleasant death... Someone might take my anger the wrong way or right way. And pull a gun and shoot me, cause me a lot of pain. You know... (Laughs). Anybody who spends the number of years I spent in prison has issues. (Id\#1)

Being aware of an impending death brought about through violence or an accident intensified fear of death caused by violence which contributes to a bad death: If you take out a gun and pull it, that's death coming to me. Oh, it creates a fear that you're going to die. The fear that you have... mhmm. Like if I ever see mine coming, yowza...(long pause)... Something that you don't see coming towards you" (Id\#18).

\section{Prolonging Life with Life Supports}

Relying on life supports was considered to interfere with normal daily routine which was contrary to facilitating a good death.

I know a guy...takes morphine tablets... now, what kind of way is that to live, you know? (chuckles)...He functions, you know, but half the time he's not there, Uh... he was just staring off into space... I don't wanna live like that. Well, they [physicians] want you to hang on until the bitter end. I uh...I better uh... cease functioning. (Id\#7)

Living a life which lacks quality was considered meaningless. A constrained life without connection to nature was not ideal. A participant expressed no desire to extend life when his functions deteriorated: "What I really abhor is the thought that I will be laid in a hospital bed with tubes down my throat or my nose, breathing on a respirator, having people to feed me and I'm not even barely conscious and I can't go outside and get any sun. I don't' want that' (Id\#1).

\section{Becoming Dependent While Entering a Dying Trajectory}

Participants feared losing control over basic physical functions. Thoughts of losing independence and relying on medical assistance were troublesome for many participants. Concern about being a burden on others might become reality when one has a chronic health condition.

I have Parkinson's disease. I don't know if it gets as bad as some of them I've seen ... if I get to the point where every...someone has to do everything for me, you know ... I don't like that idea, you know? Dying concerns me sometimes but the death itself doesn't concern me. Well as I said, having a disease where you ... you're not controlling anything, you know? You're suffering and you're drowning in your own saliva, you know. And things like that... (pause). (Id\#8)

Participants also revealed their concerns about imposing burdens on others with caregiving responsibility, especially if these caregivers would be old or frail. Relying on others for assistance was seen as imposing a hardship on the lives of significant others which were already complicated. 
Uh...make somebody responsible for taking care of me, you know? Cause I know ... anybody that would do that for me is gonna be my age or even older and ... that's too much to ask from anybody, you know? Cause their... their life might hang in the balance too because it's really strenuous you know, taking care of people that are ill. ( $\mathrm{Id} \# 7)$

\section{Dying Alone}

Dying alone was thought to be a form of bad death. As one participant remarked,

Bad death is being lonely ... no friends to be around you when you're passing away. Well, death is never really good but... (laughs) ... at least it'd be better with some friends around ... you know someone to hold your hand and whatever...I want to have some friends around during my end of life. Friends... at least get a couple of visitors once in a while before I kick the bucket... (chuckles). (Id\#4)

Dying alone reflected physical isolation as well as the sense of abandonment and separation from the social network. "I always ... for years, I never wanted to die alone in a room ... I just have seen the man and I knew he had a life and he had family and friends and all that. And he just looked so alone coming out of that room" (Id\#10). This respondent witnessed his dead friend 5 being removed from a facility. Another participant who used to live in the car with his brother for an extended period of time shared his fear of dying alone while living on the street. "When I was in the car ... that that was my dominant fear of passing away in the car, my brother and I. That was a total fear in my mind...that's one of the things I really dreaded and that's why I tried as hard as I could to get out of that situation...(long pause)" (Id\#5). Explaining how important it was to avoid dying alone, the above participant shared that he experienced a sense of relief when his brother, with whom he spent an extended period of homelessness, died while the participant was present. The participant said, "I would think his death was a good death. We were together. That's the only way... I'll leave it that way. We were together...he died in my arms" (Id\#5).

Another participant shared the loss of his family contacts and expressed his fear about his potential demise in physical isolation.

I lived on the street for five years and I haven't seen or heard from my family for the past three months... You know my wife asked me how... or what... what... how do you feel about dying alone? Meaning, I think that she meant by...by...we are separated and I'm in the situation that I am in now and if I should die in this one room ... building (transitional housing) ... uhm ... (sniffs). (Id\#3)

Participants who were not in contact with their family expressed their desire to be placed in a familiar environment where they could be surrounded with a social support network. The participant who was a veteran expressed a desire to be placed at the Veteran's Administration (VA) hospice where he would be provided with support to maintain his veteran identity.

I may not have a specific place to go, however, the places surrounded by veterans ... could share the same experience with you... We have that in common. And that's a very intensive relationship. I've met people over the years and... I go to support groups there. And ... I feel comfortable around veterans. (Id\#10)

\section{DISCUSSION}

This study explored the perceptions of a good and bad death and concerns and needs in achieving quality EOL among older homeless adults. The themes for a good death included dying peacefully, not suffering, experiencing spiritual connection, and making amends with significant others; themes for a bad death included experiencing death by accident or violence, prolonging life with life supports, becoming dependent while entering a dying trajectory, and dying alone. These themes on a good and bad death found in our study are similar to those that have been found and reported in previous studies with different populations such as terminally ill patients and various housed populations (Kehl, 2006; Steinhauser et al., 2000; Vig et al., 2002). However themes such as making amends with others, death by accident or violence, and dying alone reflect the experiences that are particularly realistic and salient to the unique and vulnerable characteristics of homeless older adults including history of trauma, poor health and mental health issues, substance use and misuse, and social isolation.

Many themes consisting of a good and bad death found among homeless older adults in our study were interrelated. Among these themes, experiencing a peaceful death was an attribute of a good death. Participants described it as the state of being unaware of pain and physical deterioration, and commonly referred to a peaceful death as "dying in sleep" which is consistent with the findings from previous studies (Hughes et al., 2008; Pierson et al., 2002; Vig \& Pearlman, 2004). The theme of peaceful death was accompanied by another theme, not suffering. Also congruent with previous studies (Payne et al., 1996; Steinhauser et al., 2000; Vig \& Pearman, 2004), participants' fear of suffering physical pain in the dying process was an important attribute 
that helped to distinguish between perceptions of a good or bad death. Concern about suffering stemmed largely from age-related infirmity which may lead to prolonged illness, and the desire to avoid such prolonged suffering 615 may not be uncommon among older adults.

The theme of not suffering was also directly related to a theme concerning a bad death, experiencing death by accident or violence. Participants in this study desired a peaceful death where one fulfills his/her life expectancy and dies naturally without prolonged pain or suffering, not a bad death marked with shock, or abrupt ending of life due to a negative event such as accident or violence. Death by accident/violence or natural death as discriminants between a good or bad death were found from previous studies with a non-homeless population (Ko, Cho, Perez, Yeo, \& Palomino, 2013; Vig et al., 2002). Although the desire to avoid death by accident or violence is shared by both homeless and housed populations, it is the level of

630 intensity of concern and fear of dying due to trauma that distinguishes the two groups. Fear of encountering a violent death is not be a remote concern for the homeless individuals because these concerns were formed from personal experiences and direct encounters with violence, drugs, and other challenging life circumstances that were life threatening.

In this study, fear about the consequence of uncontrolled anger and losing independence were important concerns voiced here. For some participants with recent

640 personal histories that highlight lack of control over important aspects of their lives, these concerns were immediate and great. They lived in harsh living environments where violence often occurred, and interacted daily with others in unstructured, unpredictable life situations while living with personal limitations in controlling anger and substance abuse. Hence, concern about not having control over their death is realistic and congruent with their life experiences.

Similarly, prolonging life by being placed on life sup-

650 port was a theme of a bad death because relying on life support was seen as a pain-inducing and unsatisfactory process. In addition, when entering a dying trajectory, the absence of independence and control over ones' life were concerns that were deemed to constitute a bad death. These views are similar to those described in the literature that documents lack of autonomy and control over decision-making and being perceived as a burden cause significant distress among patients at the EOL (Block, 2001; Payne, Langley-Evans, \& Hillier, 660 1996; Prince-Paul, 2008; Singer et al., 1999; Steinhauser Q7 et al., 2000).

Making amends with significant others and relying on spiritual connections as attributes of a good death were emphasized in contrast to the fear of dying alone, a fea- to express their affection and emotions such as thankfulness, forgiveness, and compassion to family members as found in other studies highlighting the value of social support at EOL (Ko et al., 2013; Pierson et al., 2002). A need to make amends with significant others, as well as the challenge of doing so, may be greater among the homeless population than the non-homeless population. Some homeless older adults in this study have been estranged from their family, not uncommon among homeless individuals. Stressed relationships have developed because of impaired trust and history of broken promises. Considering the limited, and often unstable social networks of homeless people, enhancing a social relationship through simple connection or mending family relationships can be a challenge at any point after sustained homelessness.

In addition to maintaining connections with other significant people, spiritual connection, affirming spiritual/religious belief in a personal relationship with God and faith in His presence in the dying process, was central to a good death for many. The attributes of God were interpreted in various ways. As with previous studies (Asgeirsdottir et al., 2013; Prince-Paul, 2008; Steinhauser et al., 2000), God was symbolized as a higher being who provides hope for a future life beyond death. Participants in this primarily religious sample generally perceived the existence of God as the endpoint in a chain of life that provides meaning and purpose. Desire for spiritual connection also overlapped with the theme of dying alone. Maintaining a personal relationship with God was found to be particularly important among some participants who had a predominant concern about dying alone. To some participants, God was seen as a doorway to an eternal life reflecting God as an attachment figure with whom the person desired to connect and from whom to find comfort at EOL (Cicirelli, 2004; Kirkpatrick, 1998; Pickard \& Nelson-Becker, 2011).

Like the finding from another study with homeless adults (Song et al., 2007), participants in this study were worried about dying alone and unnoticed. The theme of dying alone was more immediate among this group of participants who had limited supports and constrained social networks. To our participants, dying alone on the street was seen as the most undignified death and confirmed rejection, marginalization, and negligence by society. According to Seale (2004), dying alone that occurs far from home or in an isolated manner is contradictory to perceptions of a good death. This may reflect social distance which is associated with a degree of stigmatization.

Taken together, our findings highlight that to promote quality EOL care for homeless older adults, it is critical for health professionals to have a better understanding of the unique history of trauma and associated 
losses that affect many homeless individuals. Healthcare professionals need to be sensitive and respond effectively to varying emotional responses that may stem from fear of pain, suffering, and losing control oxper from less vulnerable population groups would experience. Thus, healthcare professionals are poised to be offer important assistance in EOL decision making to homeless older adults.

730 In addressing emotional and social needs of homeless individuals, it is important to recognize that social isolation may be an uneasy reality and a concern for many. The presence of family or friends may be highly valued and desired as it would serve purposes of validating life,

735 discussing shared history, and maintaining continuity of life and legacy even if the individual were dying (PrincePaul, 2008). For homeless individuals who are estranged from families or friends, assisting them to rebuild or strengthen social support may not be feasible in a short

740 period of time. Instead, it might be helpful for social and health care professionals to assist homeless individuals to find opportunities to express their feelings such as desire for forgiveness, thanksgiving, and hope to members of their social network, and to provide continuing 745 emotional support through a supportive psychotherapeutic approach (Chochinov, 2006). Religious/spiritual connection becomes increasingly important for older adults (Doka,1993; Manning, 2012). It would be important to recognize the value of religious or spiritual con-

750 nection for older adults who experience multiple losses as a major coping resource (Doka, 1993; Manning, 2012; Nelson-Becker, 2004), and facilitate provision of spiritual care.

Furthermore, promoting death within the embrace of the community, however community can be defined, may help homeless individuals at EOL. For those estranged from their family, the concept of social relationship extends beyond the circle of family or close friends. For example, as experienced by a VA partici-

760 pant, fellow veterans can play a role of surrogate family. Because people consider home as a place of familiarity and comfort (Gott, 2004), preference for placement at a VA hospice as a final destination may allow veterans to be reminded of their accomplishments, deeds of

765 patriotism, and maintaining pride (Song et al., 2007). Assessing the dimension of social relationship and meaning attached to the relationship can be an important step in assisting older homeless individuals to meet current and future needs.

\section{Limitations of the Study}

This study was the first published empirical work to explore perspectives toward a good or bad death and concerns and challenges for achieving a good death among homeless adults. Although this study adds valuable information about diverse and unique perspectives on death among a homeless population, there are some limitations to note. Our participants were recruited from a single site of transitional housing with a small sample size, so generalizability of the findings is limited. Although it was temporary, the participants were housed. Other homeless people domiciled on the street or shelters where they might be more subject to violence may have a different perspective toward a good/bad death. The participants in this study are also relatively healthy. Although participant's self-reported health and number of chronic health conditions (e.g., hypertension, arthritis, etc.) were similar to the finding from a previous study (Brown et al., 2012), the majority of our study participants were ambulatory. Older homeless adults with a poor health status or critical illness might yield a different perspective about good/bad death. Hence, future study of homeless individuals recruited from different settings such as the street, homeless shelters, and drop-in centers, as well as individuals with life-threatening illnesses or near the EOL may generate different findings. Future study should include participants in various settings with different health statuses to expand further the framework on a good and bad death.

\section{CONCLUSION}

Studies of older homeless people are few. Fewer yet explore end-of-life views and preferences, particularly surrounding the idea of what would constitute a "good" death and what would be a "bad" death. This population of marginalized older people operates with many constraints in their daily lives, some of which may be based on circumstances of early upbringing, substance abuse, or personal characteristics that they find difficult to overcome. However, they too, deserve to be included in the national conversation about end-of-life care. Their preferences and appraisals about how they hope their lives may end and their bodies surrender, what they fear and what they desire at EOL, who they would want to be present with them at their deaths, and whether and how religion and spirituality provide purpose and meaning, are all important to learn. In some ways, this has been a hidden and a marginalized population, however, as the aging population continues to expand (Administration on Aging, 2012) and rates of poverty in this group do not diminish significantly, we can assume that the number of older people who are homeless will also continue to expand. Thus, it is important for healthcare, case management, and other professionals to support the dignity and learn the desires of this group where possible. 


\section{ACKNOWLEDGMENTS}

We thank our participants at transitional housing program and staff members at Senior Community Centers of San Diego for their support.

\section{REFERENCES}

Administration on Aging. (2012). A profile of older Americans: 2012. Retrieved from http://www.aoa.gov/Aging_Statistics/Profile/ 2012/2.aspx

Asgeirsdottir, G., Sigurbjornsson, E., Traustadottir, R., Sigurdardottir, V., Gunnarsdottir, S., \& Kelly, E. (2013). "To cherish each day as it comes": A qualitative study of spirituality among persons receiving palliative care. Supportive Care in Cancer, $21,1445-1451$.

Baggett, T. P., Hwang, S. W., O'Connell, J. J., Porneala, B. C., Stringfellow, E. J., Orav, E. J., Singer, D. E., \& Rigotti, N. A (2013). Mortality among homeless adults in Boston: shifts in causes of death over a 15-year period. JAMA, 173, 189-195.

Brown, R., Kiely, D., Bharel, M., \& Mitchell, S. (2012). Geriatric syndromes in older homeless adults. Journal of General Internal Medicine, 27, 16-22.

Carr, D. (2003). A "good death" for whom? Quality of spouse's death and psychological distress among older widowed persons. Journal of Health and Social Behavior, 44, 215-232.

Chochinov, H. (2006). Dying, dignity, and new horizons in palliative end-of-life care. A Cancer Journal for Clinicians, 56, 84-103.

Cicirelli, V. (2004). God as the ultimate attachment figure for older adults. Attachment \& Human Development, 6, 371-388.

Dietz, T., \& Wright, J. D. (2005). Victimization of the elderly homeless. Care Management Journals, 6, 15-21.

Doka, K. J. (1993). Spiritual needs of dying. In K. Doka \& J. D Morgan (Eds.), Death and spirituality (death, value and meaning). Amityville, NY: Baywood Publishing Co.

Emanuel, E. J., \& Emanuel, L. L. (1998). The promise of a good death. The Lancet, 351, SII21-SII29.

Garibaldi, B., Conde-Martel, A., \& O'Toole, T. P. (2005) Self-reported comorbidities, perceived needs, and sources for usual care for older and younger homeless adults. Journal of General Internal Medicine, 20, 726-730.

Gott, M. J. G. D. S. (2004). Older people's views about home as a place of care at the end of life. Palliative Medicine, 18, 460-467.

Greenberg, G. A., \& Rosenheck, R. A. (2008). Jail incarceration, homelessness, and mental health: A national study. Psychiatric Services, 59, 170-177.

Hughes, T., Schumacher, M., Jacobs-Lawson, J. M., \& Arnold, S. (2008). Confronting death: Perceptions of a good death in adults with lung cancer. American Journal of Hospice and Palliative Medicine, 25, 39-44.

Kehl, K. A. (2006). Moving toward peace: An analysis of the concept of a good death. American Journal of Hospice and Palliative Medicine, 23, 277-286.

Kirkpatrick, L. A. (1998). God as a substitute attachment figure: A Longitudinal study of adult attachment style and religious change in college students. Personality and Social Psychology Bulletin, 24, 961-973.

880 Ko, E., Cho, S., Perez, R. L., Yeo, Y., \& Palomino, H. (2013). Good and bad death: exploring the perspectives of older Mexican Americans. Journal of Gerontological Social Work, 56, 6-25.

Ko, E., \& Nelson-Becker, H. (2013). Does end-of-life decision making matter? Perspectives of the older homeless adults. American Journal of Hospice and Palliative Medicine [epub ahead of print].
Krefting, L. (1991). Rigor in qualitative research: The assessment of trustworthiness. The American Journal of Occupational Therapy, $45,214-222$

Lebrun-Harris, L. A., Baggett, T. P., Jenkins, D. M., Sripipatana, A., Sharma, R., Hayashi, A. S. . . Ngo-Metzger, Q. (2013). Health status and health care experiences among homeless patients in federally supported health centers: Findings from the 2009 Patient Survey. Health Services Research, 48, 992-1017.

Lee, B. A., \& Schreck, C. J. (2005). Danger on the streets: Marginality and victimization among homeless people. American Behavioral Scientist, 48, 1055-1081.

Lincoln, Y., \& Guba, E. (1985). Naturalistic inquiry. New York, NY: Sage.

Manning, L. K. (2012). Spirituality as a lived experience: Exploring the essence of spirituality for women in later life. International Journal of Aging and Human Development, 75, 95-113.

McNiel, D. E., Binder, R. L., \& Robinson, J. C. (2005). Incarceration associated with homelessness, mental disorder, and co-occurring substance abuse. Psychiatric Services, 56, 840-846.

Nelson-Becker, H. (2004). Spiritual, religious, nonspiritual, nonreligious narratives in marginalized older adults: A typology of coping styles. Journal of Religion, Spirituality, and Aging, 17, $21-38$

Nelson-Becker, H. (2006). Voices of resilience: Older adults in hospice care. Journal of Social Work in End-of-Life and Palliative Care, 2(3), 87-106.

O'Connell, J. J. (2005). Premature mortality in homeless populations: A review of the literature. National Health Care for the Homeless Council. Retrieved from http://santabarbarastreetmedicine.org/ wordpress/wp-content/uploads/2011/04/PrematureMortalityFinal. pdf

Padgett, D. K. (1998). Qualitative methods in social work research. Thousand Oaks, CA: Sage Publication.

Payne, S. A., Langley-Evans, A., \& Hillier, R. (1996). Perceptions of a 'good' death: a comparative study of the views of hospice staff and patients. Palliative Medicine, 10, 307-312.

Pfeiffer, E. (1975). A short portable mental status questionnaire for the assessment of organic brain deficit in elderly patients. Journal of the American Geriatrics Society, 23, 433-441.

Pickard, J. G., \& Nelson-Becker, H. (2011). Attachment and Spiritual Coping: Theory and practice with older adults. Journal of Spirituality in Mental Health, 13, 138-155.

Pierson, C. M., Curtis, J. R., \& Patrick, D. L. (2002). A good death: a qualitative study of patients with advanced AIDS. AIDS Care, 14, 587-598.

Prince-Paul, M. (2008). Understanding the meaning of social well-being at the end of life. Oncology Nursing Forum, 35, 365-371.

Substance Abuse and Mental Health Services Administration. (2011). Current statistics on the prevalence and characteristics of people experiencing homelessness in the United States [Electronic Version] Retrieved from http://homeless.samhsa.gov/ResourceFiles/hrc factsheet.pdf

Salem, B. E., Nyamathi, A. M., Phillips, L., Menters, J. C., Sarkisian, C., \& Leake, B. (2013). Correlates of frailty among homeless adults. Western Journal of Nursing Research, 35, 1128-1152.

Seale, C. (2004). Media constructions of dying alone: A form of "bad death". Social Science \& Medicine, 58, 967-974.

Singer, P. A., Martin, D. K., \& Kelner, M. (1999). Quality end-of-life care: Patients\&\#39; perspectives. The Journal of the American Medical Association, 281, 163-168.

Song, J., Bartels, D. M., Ratner, E. R., Alderton, L., Hudson, B., \& Ahluwalia, J. S. (2007). Dying on the streets: homeless persons' concerns and desires about end of life care. Journal of General Internal Medicine, 22, 435-441. 
Song, J., Ratner, E. R., \& Bartels, D. M. (2005). Dying while homeless: Is it a concern when life itself is such a struggle? The Journal of Clinical Ethics, 16(3), 251-261.

Song, J., Ratner, E. R., Bartels, D. M., Alderton, L., \& Ahluwalia, J. S. (2007). Experiences with and attitudes toward death and dying among homeless persons. Journal of General Internal Medicine, 22, 427-434.

Steinhauser, K. E., Christakis, N. A., Clipp, E. C., McNeilly, M., Mclntyre, L., \& Tulsky, J. A. (2000). Factors considered important at the end of life by patients, family, physicians, and other care providers. The Journal of the American Medical Association, 284, 2476-2482.

Steinhauser, K. E., Clipp, E. C., McNeilly, M., Christakis, N. A., McIntyre, L. M., \& Tulsky, J. A. (2000). In search of a good death: Medicine, 132, 825-832.

Tarzian, A. J., Neal, M. T., \& O’Neil, J. A. (2005). Attitudes, experiences, and beliefs affecting end-of-life decision-making among homeless individuals. Journal of Palliative Medicine, 8(1), 36-48.

van der Geest, S. (2004). Dying peacefully: Considering good death and bad death in Kwahu-Tafo, Ghana. Social Science \& Medicine, 58, 899-911.

Vig, E. K., Davenport, N. A., \& Pearlman, R. A. (2002). Good deaths, bad deaths, and preferences for the end of life: A qualitative study of geriatric outpatients. Journal of the American Geriatrics Society, 50, $1541-1548$

Vig, E. K., \& Pearlman, R. A. (2004). Good and bad dying from the perspective of terminally ill men. Archives of Internal Medicine, 164, 977-981.

Watts, T. (2012). End-of-life care pathways as tools to promote and support a good death: A critical commentary. European Journal of Cancer Care, 21(1), 20-30. 